\title{
Preparatory and precursory processes leading up to the 2014 phreatic eruption of Mount Ontake, Japan
}

\author{
Aitaro Kato ${ }^{1,2^{*}}$, Toshiko Terakawa ${ }^{1}$, Yoshiko Yamanaka ${ }^{1}$, Yuta Maeda ${ }^{1}$, Shinichiro Horikawa ${ }^{1}$, Kenjiro Matsuhiro ${ }^{1}$ \\ and Takashi Okuda ${ }^{1}$
}

\begin{abstract}
We analyzed seismicity linked to the 2014 phreatic eruption of Mount Ontake, Japan, on 27 September 2014. We first relocated shallow volcano tectonic (VT) earthquakes and long-period (LP) events from August to September 2014. By applying a matched-filter technique to continuous waveforms using these relocated earthquakes, we detected numerous additional micro-earthquakes beneath the craters. The relocated VT earthquakes aligned on a near-vertical plane oriented NNW-SSE, suggesting they occurred around a conduit related to the intrusion of magmatic-hydrothermal fluids into the craters. The frequency of $V T$ earthquakes gradually increased from 6 September 2014 and reached a peak on 11 September 2014. After the peak, seismicity levels remained elevated until the eruption. b-values gradually increased from 1.2 to 1.7 from 11 to 16 September 2014 then declined gradually and dropped to 0.8 just before the eruption. During the 10-min period immediately preceding the phreatic eruption, VT earthquakes migrated in the up-dip direction as well as laterally along the NNW-SSE feature. The migrating seismicity coincided with an accelerated increase of pre-eruptive tremor amplitude and with an anomalous tiltmeter signal that indicated summit upheaval. Therefore, the migrating seismicity suggests that the vertical conduit was filled with pressurized fluids, which rapidly propagated to the surface during the final 10 min before the eruption.
\end{abstract}

Keywords: Mount Ontake; 2014 phreatic eruption; Precursor; Earthquake; Relocation; Matched-filter technique; b-value

\section{Findings}

Introduction

Mount Ontake is located at the southern end of the Norikura volcanic zone, central Japan (Fig. 1a). In 1979, Mount Ontake produced its first phreatic eruption in recorded history, ejecting ash, gas, and debris into the sky (volcanic explosivity index $(\mathrm{VEI})=2$, Smithsonian 2015). The 1979 eruption was followed by minor phreatic explosions in 1991 and 2007 (e.g., Nakamichi et al. 2009; Japan Meteorological 2014). On 27 September 2014, at 11:52 a.m. IST (UTC + 9), Mount Ontake produced another phreatic (steam type) eruption, spraying volcanic ash, gas, and debris on surrounding areas. Based on ejecta volume and the maximum ash column height of

\footnotetext{
* Correspondence: aitaro@seis.nagoya-u.ac.jp

${ }^{1}$ Earthquake and Volcano Research Center, Graduate School of

Environmental Studies, Nagoya University, Furo-cho, Chikusa-ku, Nagoya 464-8601, Japan

Earthquake Research Institute, University of Tokyo, 1-1-1 Yayoi, Bunkyo-ku, Tokyo 113-0032, Japan
}

$\sim 7000 \mathrm{~m}$, the VEI for this eruption was 2 (Earthquake Research Institute in the University of Tokyo 2014; Japan Meteorological 2014). The 2014 eruption resulted in the deaths of 57 climbers, with a further 6 missing and presumed dead (e.g., Cyranoski 2014). The 2014 phreatic eruption had similar features to the 1979 eruption, including eruption style and rough positions of vents.

It is generally difficult to predict the timing and likely size (VEI) of phreatic eruptions because their measurable precursors are weak and highly localized (e.g., Barberi et al. 1992) or absent (e.g., Maeda et al. 2015). Phreatic eruptions often occur during periods of elevated seismicity and high heat flow through the volcanic system, which can be potential precursors (e.g., Barberi et al. 1992; Aoyama and Oshima 2008; Mordret et al. 2010). However, the fundamental processes related to preparatory and precursory stages of phreatic eruptions are poorly known. Because seismicity is one of the most powerful tools for identifying volcanic processes that could precede phreatic

\section{Springer}




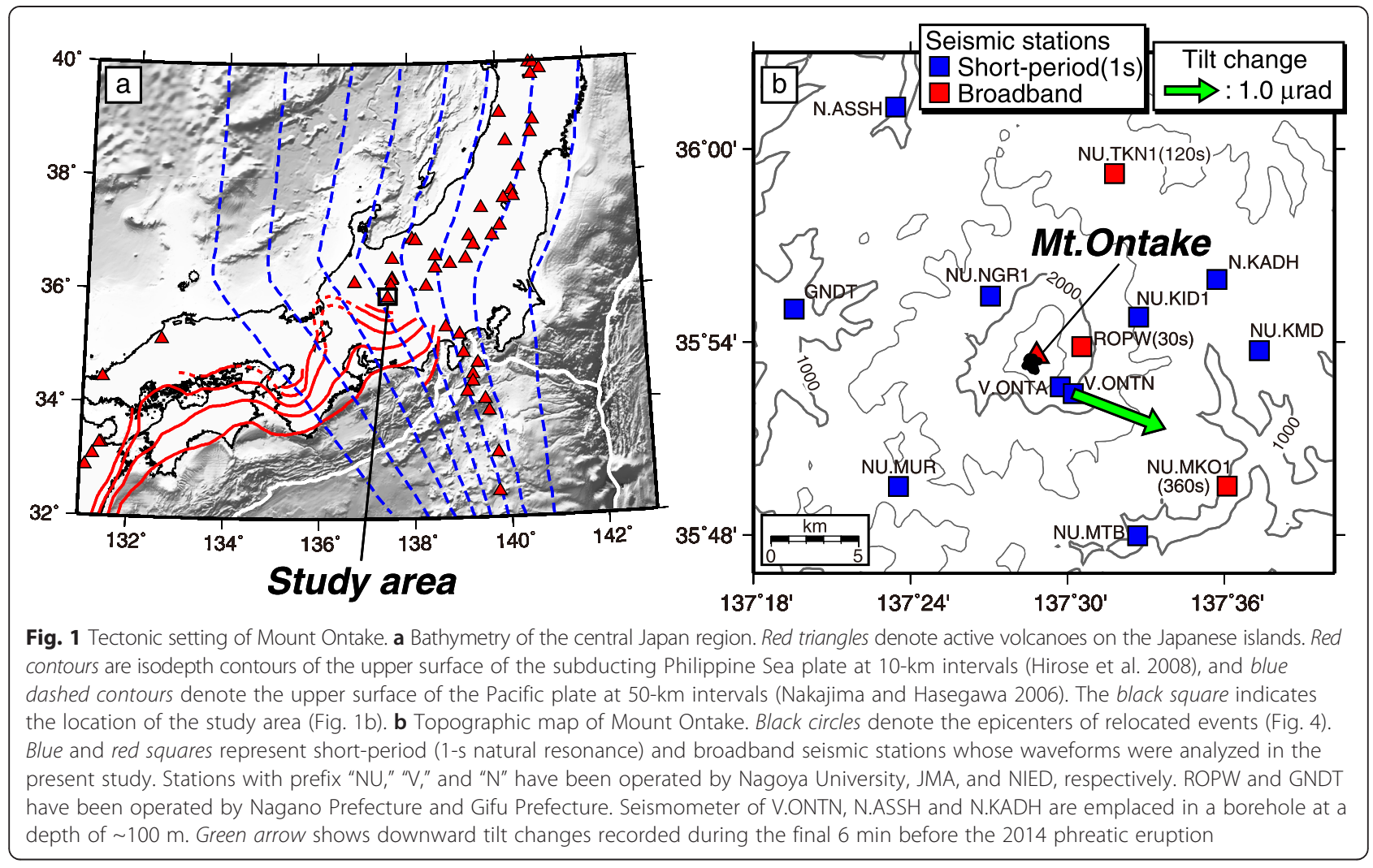

eruptions (e.g., Chouet 1996; Roman and Cashman 2006), it is essential to investigate the spatial-temporal evolution of earthquakes leading up to the 2014 phreatic eruption of Mount Ontake.

A manually constructed earthquake catalog for the region under the summit of Mount Ontake shows that an average monthly rate of volcano tectonic (VT) and long-period (LP) earthquakes (magnitude $<1.0$ ) during 1 year before the eruption was about 3.3/month, and $0.17 /$ month, respectively (Japan Meteorological 2014). Then, the micro-seismicity sharply increased beginning around 2 weeks before the eruption. To constrain the fundamental processes associated with the phreatic eruption, we relocated VT and LP earthquakes beneath the summit, using double differential travel times extracted from waveform cross-correlation method. We then searched for new earthquakes by applying a matched-filter detection technique (e.g., Shelly et al. 2007; Kato et al. 2013) to continuous seismograms recorded near the Mount Ontake summit (Fig. 1b) from 23 August to 30 September 2014, using the waveforms of well-located earthquakes as template events. We discuss the spatial-temporal evolution of the elevated seismicity, including temporal changes in b-values from the beginning of September to the time of eruption. Furthermore, we focus on the immediate precursors that began less than $10 \mathrm{~min}$ before the phreatic eruption, including the up-dip and lateral migrations of earthquake hypocenters, an accelerated increase in the amplitudes of pre-eruptive tremors, and tiltmeter changes observed near the summit.

\section{Data and methods}

We used three-component velocity seismograms retrieved at 13 seismic stations around the summit of Mount Ontake, operated by Nagoya University, the Japan Meteorological Agency (JMA), the National Research Institute for Earth Science and Disaster Prevention (NIED), Nagano Prefecture, and Gifu Prefecture (Fig. 1b). Data were continuously recorded by each station at a sampling rate of $100 \mathrm{~Hz}$ (the station ROPW restarted the recording from 19 September 2014). Most earthquakes before the eruption were classified as VT earthquakes, having clear high-frequency P- and $\mathrm{S}$-wave arrivals with broadband frequencies greater than $5 \mathrm{~Hz}$ (Fig. 2a). In contrast to VT earthquakes, LP events were characterized by a weak high-frequency onset, quasi-monochromatic oscillations with a peak frequency near $1.5 \mathrm{~Hz}$, and durations of more than $20 \mathrm{~s}$ (Fig. 2b). Comparisons of the spectrograms show a marked difference between VT and LP earthquakes in terms of the spectral amplitude of the seismogram versus frequency. These classifications are similar to those proposed previously for other volcanoes (e.g., Lahr et al. 1994; Chouet 1996). 

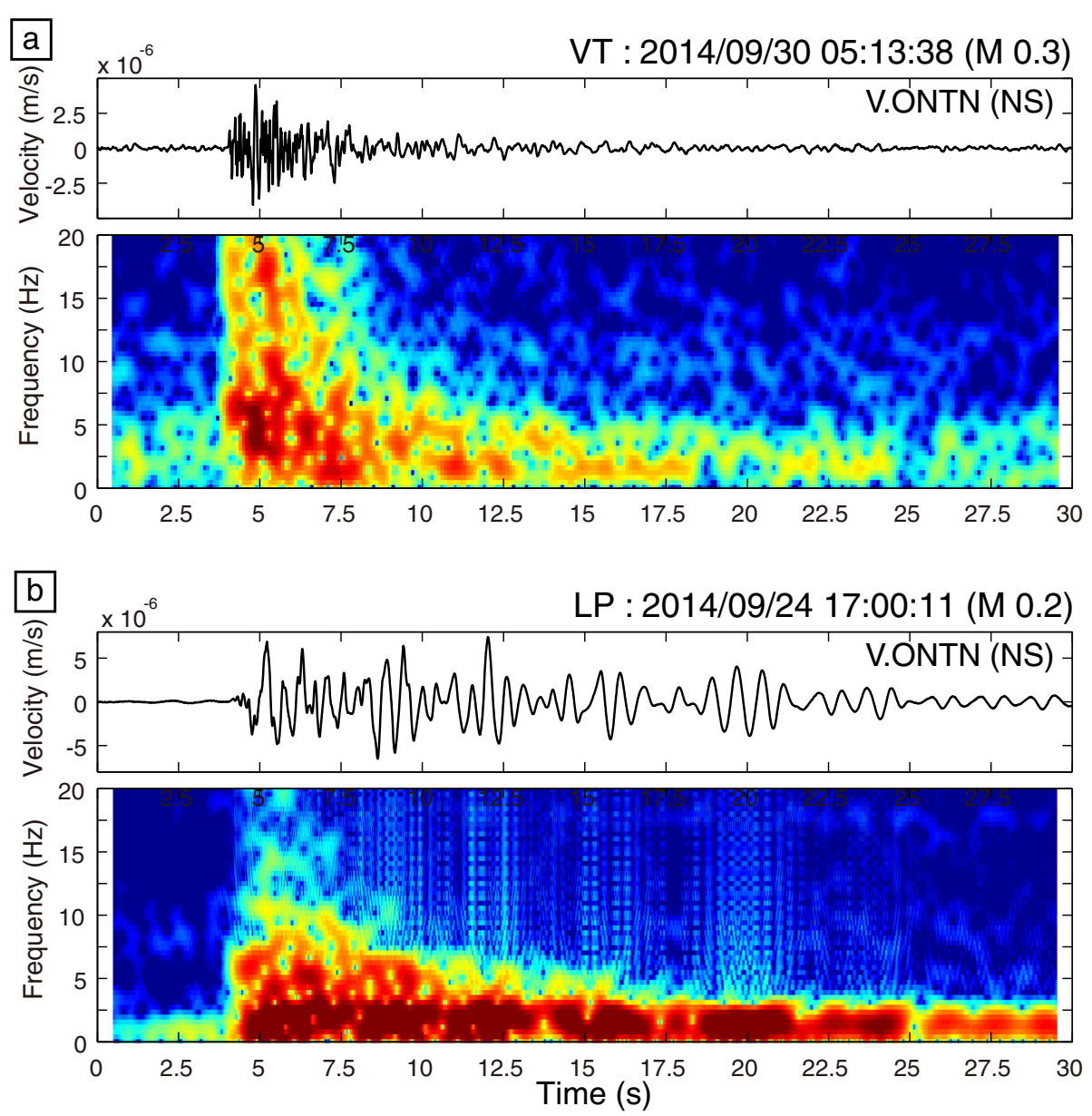

Fig. 2 Velocity seismograms and associated spectrograms of a VT earthquake (a) and an LP event (b) recorded at the V.ONTN station (NS component). Each spectrogram is calculated from the spectral amplitudes of velocity versus frequency in a moving 1-s window running through the entire seismogram (98\% overlap), as shown above each spectrogram

\section{Relocation of template earthquakes}

We visually picked the arrival times of the P- and Swaves of 96 VT earthquakes between 31 August and 30 September 2014 and of 2 LP earthquakes on 16 and 24 September 2014. The number of P- and S-wave arrival times for each event exceeded 8 and 4 , respectively. The picking accuracy of P- and S-wave arrivals for VT earthquakes was estimated to be $0.04 \mathrm{~s}$ and $0.1 \mathrm{~s}$, respectively. We relocated these 98 template earthquakes by applying a relocation algorithm (Zhang and Thurber 2003) to both arrival times and differential arrival times fixing the velocity model. Our P-wave velocity model was constructed from previous seismic surveys (Fig. 3), assuming a Poisson ratio of 0.25 . For depths above sea level, we used a P-wave velocity structure determined by seismic surveys at other active volcanoes in Japan because the velocity structure of Mount Ontake has not been previously investigated (e.g., Tanaka et al. 2002; Aoki et al. 2009). For the deeper velocity structure, we used a regional velocity model for central Japan based on Ikami et al. (1986) and Kato et al. (2007).
The numbers of absolute arrival times used in the relocation are 979 for P-waves and 722 for S-waves. The numbers of differential arrival times for the manually picked P- and S-waves are 6697 and 4003, respectively. We also used differential arrival times obtained by waveform cross-correlation method. The correlation measurements were conducted using a 0.8 -s window length beginning $0.4 \mathrm{~s}$ before each visually picked arrival time for waveform data bandpass filtered between 8 and $16 \mathrm{~Hz}$. This produced a data set of differential arrival times that contained 2477 P-wave and $367 \mathrm{~S}$-wave observation pairs, all of which had a normalized cross-correlation coefficient of $\geq 0.90$. The root mean square of the travel time residual was reduced from 0.118 to $0.06 \mathrm{~s}$ after 21 iterations.

To assess the reliability of the relocated hypocenters, we applied a statistical resampling approach termed as bootstrap method to the events. We calculated synthetic arrival time data by adding random Gaussian noises with a standard deviation of $0.05 \mathrm{~s}$ (average of $0 \mathrm{~s}$ ) to the observed arrival time data. We then relocated events 


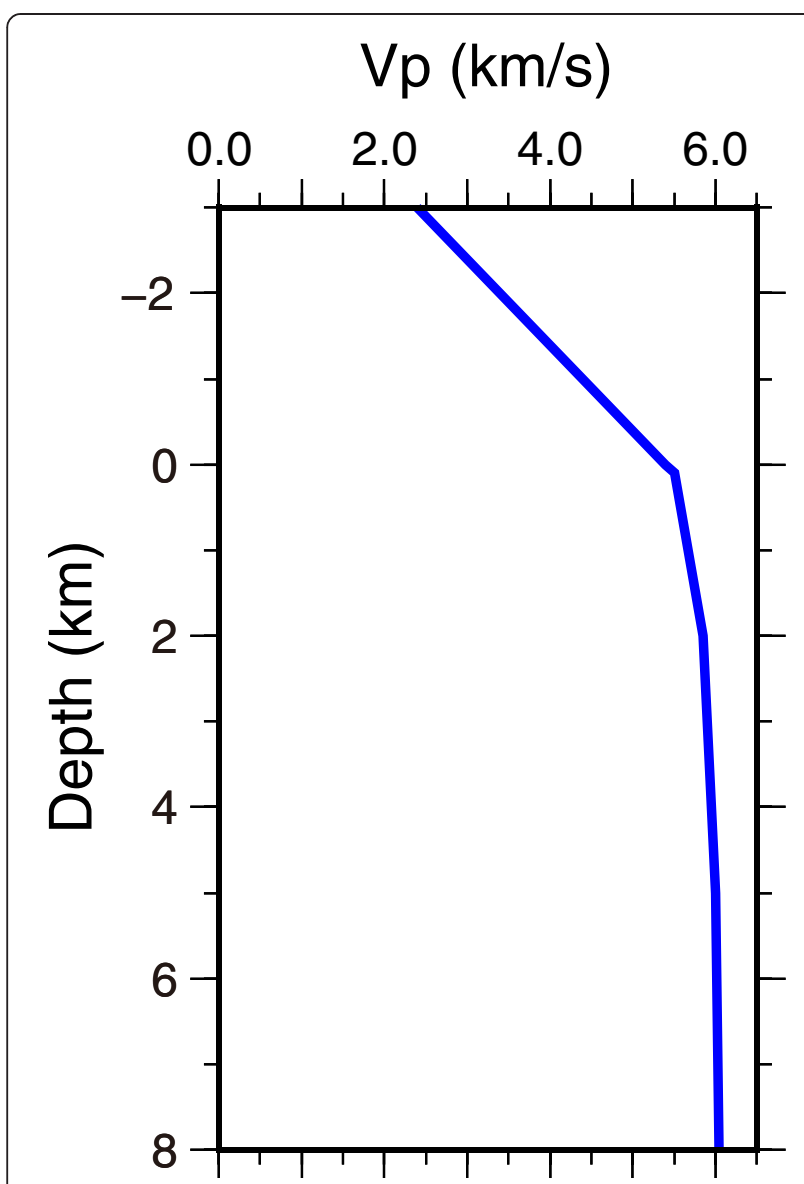

Fig. 3 One-dimensional P-wave velocity structure employed for the earthquake relocation. We assumed a Poisson's ratio of 0.25

to determine the shift in location based on the corrupted arrival times. The process was repeated 500 times with new Gaussian noise generated for each iteration. Based on the cumulative results, the average horizontal and depth errors are 160 and $340 \mathrm{~m}$, respectively. The error ellipsoids of each hypocenter on the horizontal surface are slightly elongated along the NE-SW directions. The hypocenter accuracy of the LP events are not so well compared with that of the VT events, due to a shortage of high-frequency components at onsets of P- and S-wave arrivals. Furthermore, absolute locations were sensitive to the assumed velocity structure, but the relative distribution of earthquake was less sensitive. For an example, relocated hypocenters tend to be deeper and more clustered for an assumed velocity model with a small velocity gradient near the surface.

\section{Detection of earthquakes by a matched-filter technique}

To more precisely characterize pre- and post-eruption temporal changes in seismicity, we searched for additional events using a matched-filter technique (e.g., Shelly et al. 2007; Kato et al. 2012, 2013). Waveform data from the relocatable earthquakes were used to construct a dictionary of template events. We then matched these waveforms against continuous data recorded between 23 August 2014 and 30 September 2014.

To search for VT earthquakes, both continuous data and template waveforms were bandpass filtered from 4 to $12 \mathrm{~Hz}$ and decimated to $50 \mathrm{~Hz}$. Similarly, for LP earthquakes, data were bandpass filtered from 0.5 to $1 \mathrm{~Hz}$ and decimated to $10 \mathrm{~Hz}$. As template events, we used the relocated earthquakes in Fig. 4. A synthetic Swave arrival time for each template event was calculated using the one-dimensional seismic velocity structure used for relocation. To obtain template event waveforms and target waveforms, we used a 4.0-s window for VT earthquakes and a 20.0-s window for LP earthquakes, beginning $2.0 \mathrm{~s}$ prior to the synthetic S-wave arrival time. We computed correlation coefficients between a template event waveform and a target waveform using incremental detection-window shifts of $0.02 \mathrm{~s}$ for VT earthquakes and $0.1 \mathrm{~s}$ for LP events. We set a threshold for event detection equal to 10 times the median absolute deviation (MAD) of the average correlation coefficients calculated throughout the day of interest for VT earthquakes and 13 times the MAD for LP events. To remove multiple detections, we allocated the location of the detected event to that of the template event with the highest correlation coefficient within the \pm 4 -s window for VT earthquakes and \pm 20 -s window LP events. Fig. 5 shows an example of waveforms at the detection time for a template event. We identified 3300 VT and 28 LP earthquakes (Fig. 6). For more details of the matched-filter technique, see Kato et al. (2013).

\section{Calculation of $b$-values}

Using the newly constructed earthquake catalog, we calculated b-values using the maximum likelihood estimate (Utsu 1965) in overlapping 400-event windows shifted by 20 events per calculation. We simultaneously determined the temporal change in the catalog completeness magnitude using the goodness-of-fit method (Wiemer and Wyss 2000). We used the $90 \%$ goodness-of-fit level as the completeness magnitude, which implies that $90 \%$ of the variability in the observed frequency-magnitude distribution can be modeled with a synthetic power law.

\section{Results}

Figure 4a shows that the relocated hypocenters are tightly clustered to the southwest of the Mount Ontake summit, with 500-m absolute offset. The VT and LP events occurred in the same area at shallow depths close to sea level. The relocated hypocenters (98 events) roughly coincide with alignments of eruptive vents identified by remote sensing images obtained by Geospatial Information Authority of Japan (Geospatial Information Authority of Japan 2014) (white masked area in Fig. 4a). The epicentral distribution was oriented roughly NNW-SSE. Depth 

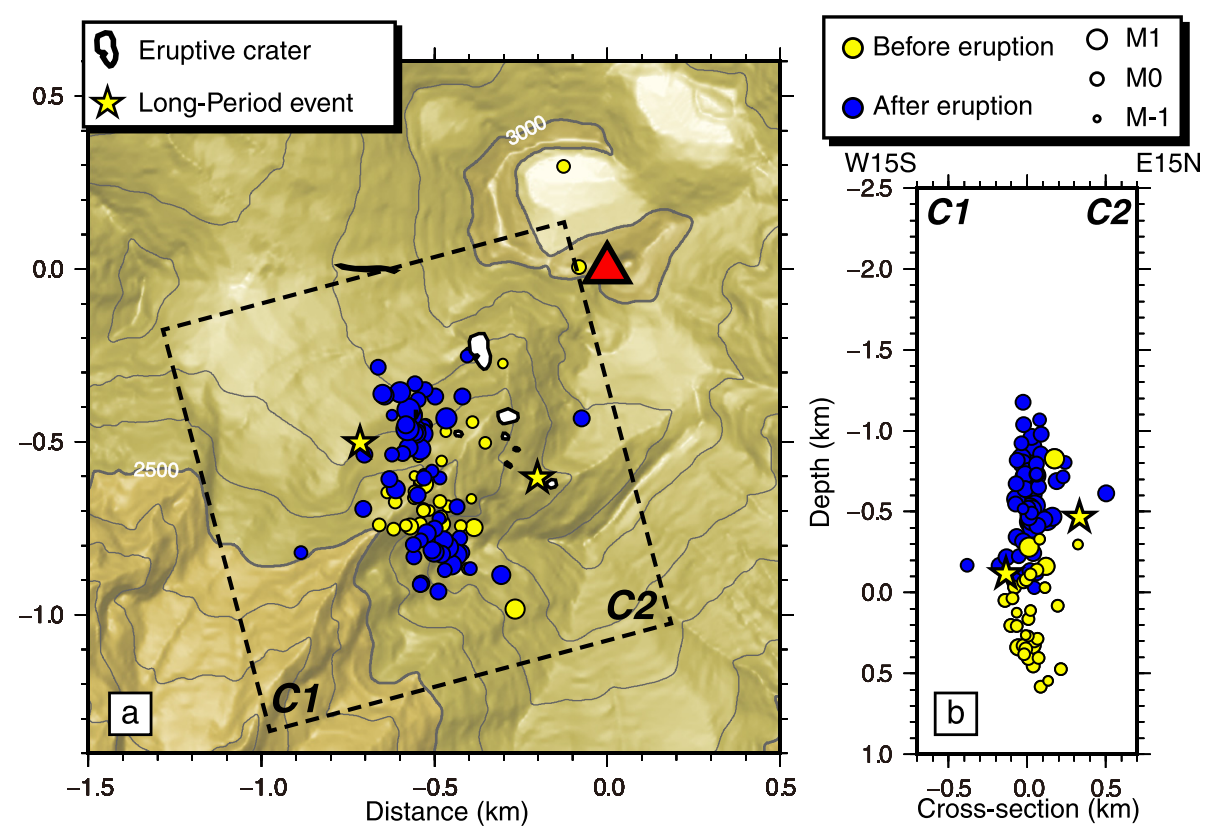

Fig. 4 Earthquake relocations. a Epicentral distribution of the relocated earthquakes superimposed on topography. Yellow and blue circles denote VT earthquakes before and after the 2014 eruption, respectively. Circles are scaled to magnitude. Yellow stars represent LP events prior to the eruption. White masked areas and a red triangle are eruptive craters identified by remote sensing (Geospatial Information Authority of Japan 2014) and the summit of Mount Ontake, respectively. $\mathbf{b}$ Vertical depth section of the relocated hypocenters perpendicular to the NNW-SSE orientation. The positive vertical axis is below sea level

section for relocated hypocenters shows that the earthquakes are aligned along a vertically dipping plane (Fig. 4b) approximately $1.5 \mathrm{~km}$ high (dip direction) and $0.7 \mathrm{~km}$ wide. Additionally, while VT earthquakes before the eruption were located at greater depths, post-eruption VT earthquakes occurred at depths shallower than the preceding seismicity by approximately $1.0 \mathrm{~km}$.

Figure $6 \mathrm{a}, \mathrm{b}$ shows space-time diagrams of the newly detected seismicity. From 6 September 2014, the source region of VT earthquakes slightly expanded vertically as well as laterally along the NNW-SSE feature, accompanied by a gradual increase in VT and LP earthquakes. The VT earthquake rate peaked on 11 September and remained relatively high until the eruption, with a slight decay (Fig. 6c). The number of LP events showed a sharp increase between 15 and 16 September, a delay of about 5 days from the peak of VT seismicity.

After the eruption, the depths of VT earthquakes became systematically shallower by $\sim 1.0 \mathrm{~km}$ relative to pre-eruption hypocenters (Fig. 6b), even after adding numerous events with the matched-filter technique. Furthermore, we recognized a slight lateral expansion of the earthquake alignment in the NNW-SSE direction just after the eruption (Fig. 6a).

Based on the newly detected seismicity, we identified several immediate precursors to the phreatic eruption of 27 September 2014. About $10 \mathrm{~min}$ prior to the eruption, hypocenters of VT earthquakes migrated in the up-dip direction as well as laterally along the NNW-SSE feature in a near-vertical plane (Fig. 7a, b). The rate of lateral earthquake migration ranged from 0.35 to $0.7 \mathrm{~m} / \mathrm{s}$ (Fig. 7a). Along the depth section, the VT earthquakes become gradually shallower from 11:40 to 11:45 (JST) on 27 September then rapidly rose toward the craters (Fig. 7b). Simultaneously, the amplitudes of the pre-eruptive tremors increased at an accelerated rate (Fig. 7c). Each spike in the pre-eruptive tremor corresponds to a VT earthquake detected by the matched-filter technique, resulting in a gradual increase in large-magnitude events (Fig. 7a, b). In addition to both earthquake migrations and accelerating tremor amplitude, tiltmeter signals were also characterized by downward acceleration in the ESE direction, beginning $\sim 6$ min before the phreatic eruption (Fig. 1b and $7 \mathrm{~d})$.

After the peak in VT seismicity on 11 September 2014, b-values gradually increased from $\sim 1.2$ to $\sim 1.7$ on 16 September 2014 (Fig. 8). Shortly after attaining this maximum, b-values declined until the eruption, with only minor fluctuations. This reduction in b-values is well correlated with an increased frequency of relatively large-magnitude events after 21 September 2014 (Fig. 6d). The final drop in b-values was due to the relative increase in large-magnitude events during the $10 \mathrm{~min}$ immediately preceding the eruption. The representative plots of frequency-magnitude distributions shown in Fig. 8b indicate that the temporal changes in b-values described above are statistically significant. 


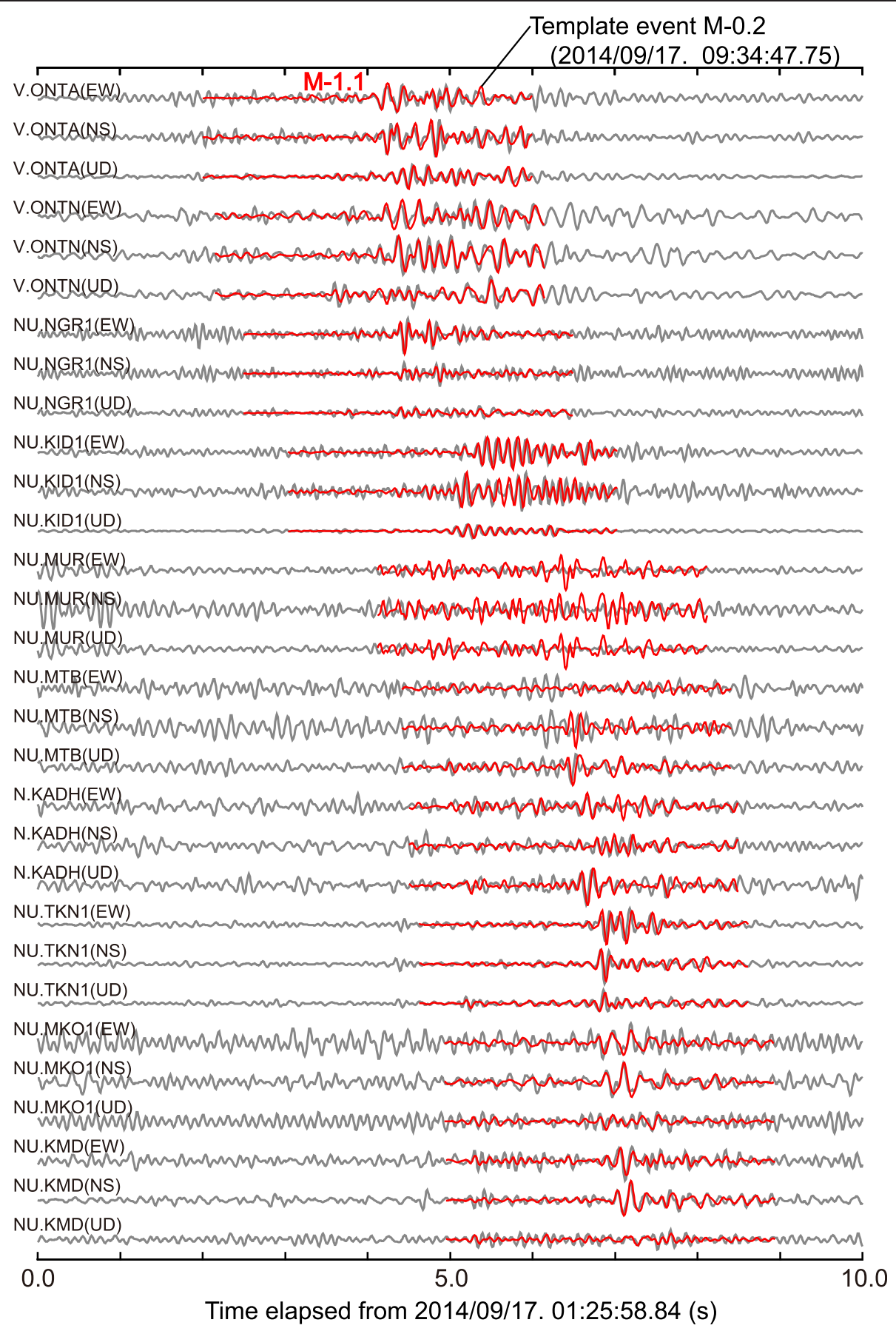

Fig. 5 An example of waveforms at the detection time of M-1.1 event using a template event (2014/09/17. 09:34:47.75). The gray and red lines are the continuous and template event waveforms for seismic stations aligned according to epicentral distance, respectively. The window of the template event is $4 \mathrm{~s}$, starting from $2.0 \mathrm{~s}$ prior to the synthetic S-wave arrival time. The station names and components are given to the left of each trace. Waveforms were bandpass filtered between 4 and $12 \mathrm{~Hz}$, and the amplitudes of waveforms were normalized by the maximum value at each station

\section{Discussion and conclusions}

By relocating shallow VT and LP earthquakes and applying a matched-filter detection technique to seismic data recorded before the 2014 phreatic eruption of Mount Ontake, we reconstructed the earthquake catalog beneath the craters, which provides new insights into the preparatory and precursory stages of the eruption. The relocated VT earthquakes are aligned on a nearvertical plane oriented NNW-SSE, defining a nearvertical conduit related to the intrusion of hydrothermal fluids (steam, gases, and liquid water) into the craters (Fig. 4). 


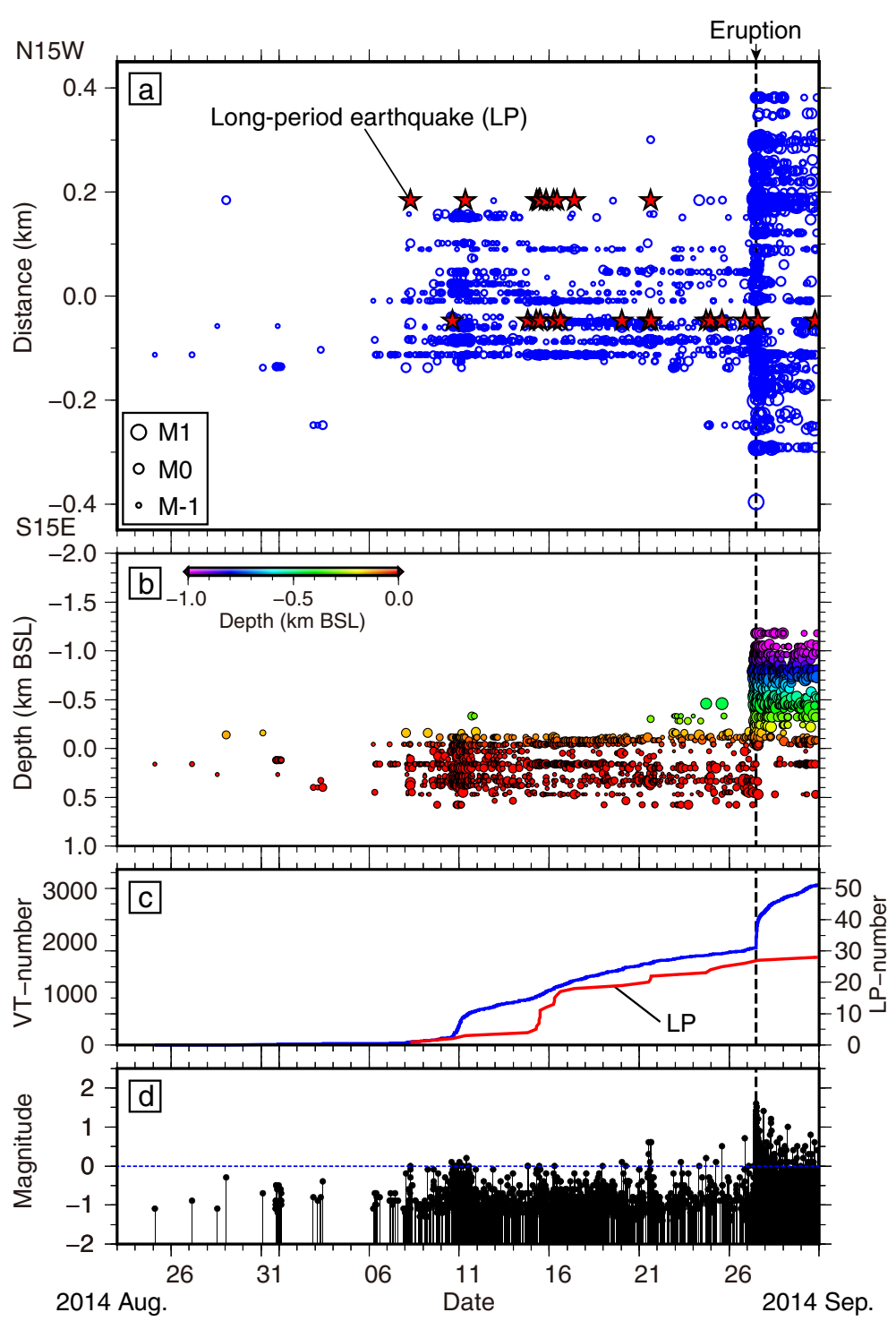

Fig. 6 Seismicity detected by matched-filter processing. a Space-time diagram of all detected events before and after the 2014 phreatic eruption, from 23 August to 30 September. Blue circles and red stars denote VT earthquakes and LP events, respectively. The diagram shows earthquake origin times and locations projected onto the strike of the hypocenter alignments. b Depth variations in detected $V T$ earthquakes over time. Circles are scaled to magnitude and color-coded to depth (below sea level (BSL), with positive values being below sea level). c Cumulative number of VT earthquakes (blue curve) and LP events (red curve) over time. $\mathbf{d}$ Magnitude versus time

The initial acceleration of VT seismicity, as well as LP events during the middle of September, suggests that infiltration of hot fluids triggered the abundant seismicity beneath the craters (Fig. 9a). Following the peak in the occurrence rate of VT earthquakes, shallow LP events sharply increased. It is widely believed that the source mechanism of shallow LP events is resonant excitation of a fluid-filled crack (e.g., Chouet 1996; Kumagai and Chouet 2000; Waite et al. 2008). In the present case, the excitation could be driven by hydrothermal fluids. We thus infer that hydrothermal fluids infiltrated into preexisting faults/cracks during the period of LP activity.
Before the minor phreatic eruption in 2007, a verylong-period (VLP) earthquake with equivalent moment magnitude 3.4, as well as a burst of LP events, was recorded by broadband seismic stations (Nakamichi et al. 2009). Waveform inversion yielded a location $0.6 \mathrm{~km}$ above sea level beneath the craters of Mount Ontake and suggests that the source mechanism was inflation followed by deflation of the crack associated with vaporization of water and the subsequent discharge of steam into the hydrothermal system. Interestingly, the azimuth of the crack exciting the VLP (N20W) was sub-parallel to that of the vertical conduit indicated by the relocated hypocenters 


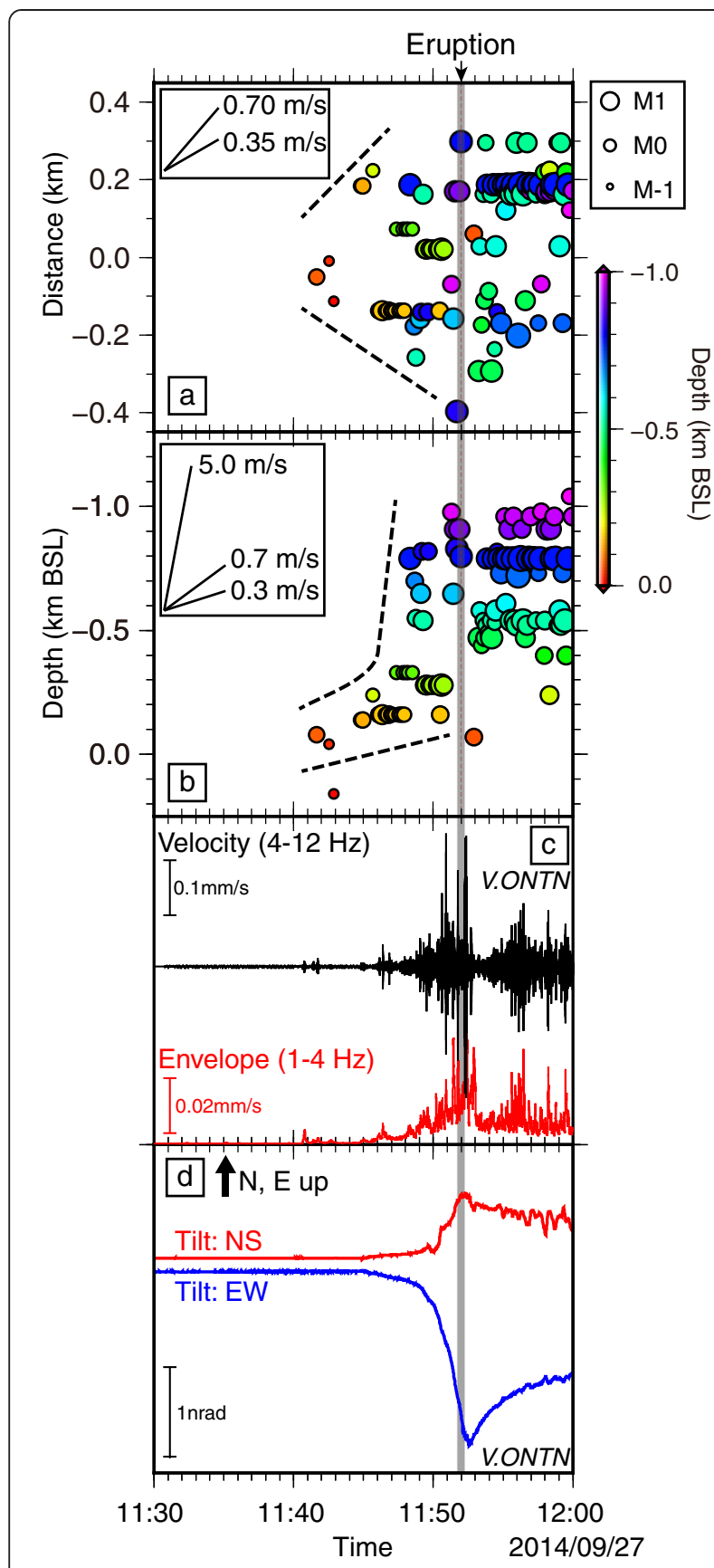

Fig. 7 Precursors of the 2014 phreatic eruption. a Horizontal distance of detected VT earthquakes from 11:30 to 12:00 JST on 27 September 2014, projected onto the strike of the hypocenter alignments (N15W-S15E). Circles are scaled to magnitude and color-coded to depth. Black dashed lines approximate the locations of the fronts of earthquake migrations. b Depth variations in VT earthquakes, colored to depth. Circles are scaled to magnitude. Black dashed lines approximate the locations of the fronts of earthquake migrations. c Bandpass filtered waveform between 4 and $12 \mathrm{~Hz}$ (black curve) and envelope between 1 and $4 \mathrm{~Hz}$ (red curve) recorded at the V.ONTN station. $\mathbf{d}$ Time series of tiltmeter records observed at the V.ONTN station. NS and EW components denote the northward and eastward ground-up components, respectively in the present study $(\mathrm{N} 15 \mathrm{~W})$. Whether reactivation of an old conduit or coincidental similarity, the similar geometries suggest the preferred orientation of pre-existing cracks along NNW-SSE beneath the summit of Mount Ontake. However, a VLP event was not recorded during the elevated VT seismicity before the 2014 eruption.

During the period of increased LP seismicity, b-values increased to nearly 1.7 (Fig. 8). Based on spatial mapping of b-values at many volcanoes (e.g., Wyss et al. 1997; McNutt 2005; Bridges and Gao 2006), high b-values have been widely observed in areas with high thermal gradients due to the interaction of hot fluids (vapors, gases, and liquid water) with adjacent magma bodies. Thus, we interpret that the high b-values reflect an increase in the density of smaller faults/cracks due to the infiltration of hot fluids (Fig. 9a).

Between 11 and 16 September 2014, the combination of an increase in LP events and an increase in b-values suggests that hot fluids infiltrated into pre-existing faults/ cracks above a magma chamber. Fluid pressures within the faults/cracks further increased, resulting in a reduction of the effective normal stress on faults/cracks (e.g., Hubbert and Rubey 1959; Terakawa et al. 2013; Terakawa 2014). This reduction in fault strength facilitated the growth of small faults/cracks into larger ones, producing highermagnitude earthquakes (Fig. 6d), which can also explain the gradual decrease in b-values after 16 September 2014 (Fig. 8).

Based on these observations, we postulate that hot fluids were pervasive to pre-existing faults/cracks and pressurized by heat supplied from the underlying magma chamber from the middle of September 2014 (Fig. 9a). The shallow portion beneath the summit perhaps withstood stress concentration derived from the increase in internal pressure of the underlying hydrothermal system.

During the $10 \mathrm{~min}$ prior to the phreatic eruption, the up-dip and lateral migrations of VT earthquakes coincided with an increase in pre-eruptive tremor amplitude and an anomalous tiltmeter signal near the craters. Because the tiltmeter signal was consistent with summit upheaval (Figs. 1 and 9b), the migrating seismicity indicates the rapid propagation of pressurized fluids (vapor, gases, and liquid water) through a vertical conduit. The lateral propagating speed of the conduit tip ranged from 0.35 to $0.7 \mathrm{~m} / \mathrm{s}$ (Fig. 7a). Interestingly, these speeds are roughly comparable to those of migrating VT earthquakes triggered by dike intrusion (0.06$0.3 \mathrm{~m} / \mathrm{s}$ ) (e.g., Hayashi and Morita 2003; Shelly and Hill 2011). Finally, failure of the sealed surface of the vertical conduit led to the 2014 phreatic eruption. The sealed surface may be produced by the precipitation of altered clay minerals or hydrothermal secondary deposits near the surface (e.g., Bertrand et al. 2012; Maeda et al. 2015). 

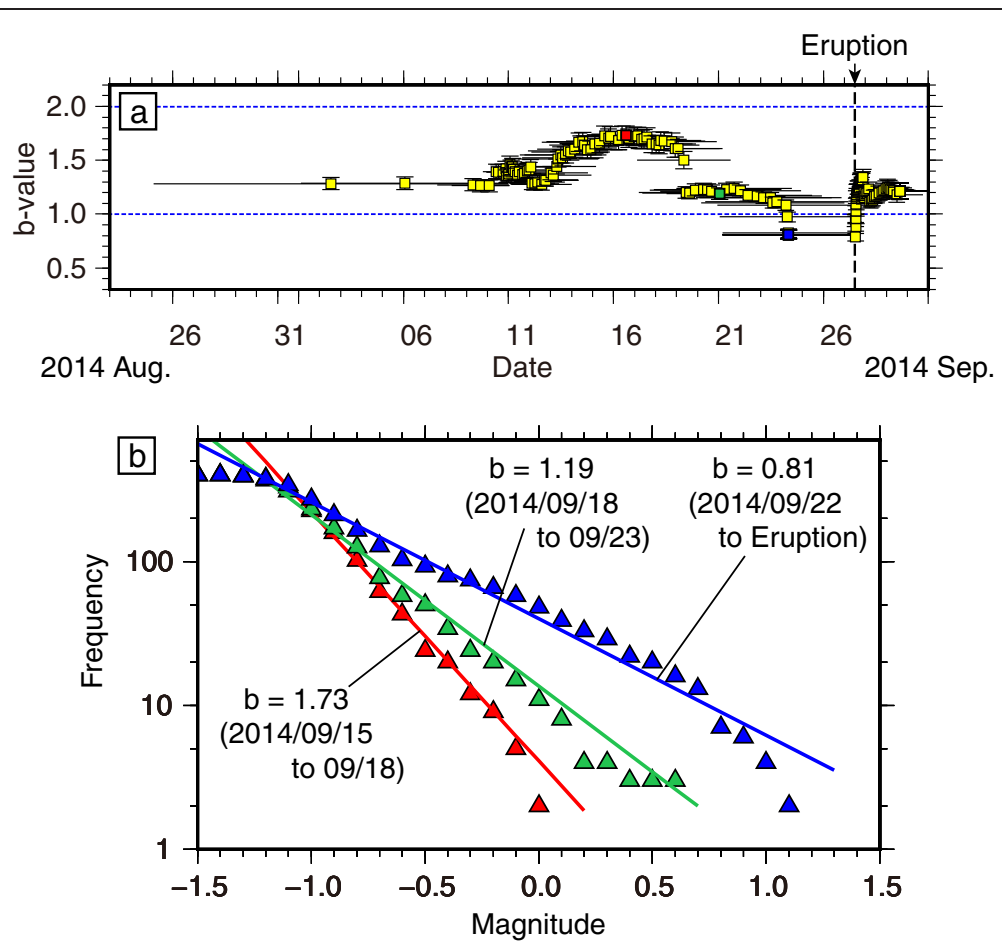

Fig. 8 Temporal changes in b-values. a Calculated b-values are represented by yellow squares. Uncertainties are indicated by vertical and horizontal error bars. b-value uncertainties (vertical error bars) were estimated following Shi and Bolt (1982). The horizontal error bars indicate the time window used for each b-value calculation (containing 400 events). Colored squares represent the selected magnitude-frequency distributions given by the triangles in (b). b Selected cumulative magnitude-frequency distributions

a Middle of September
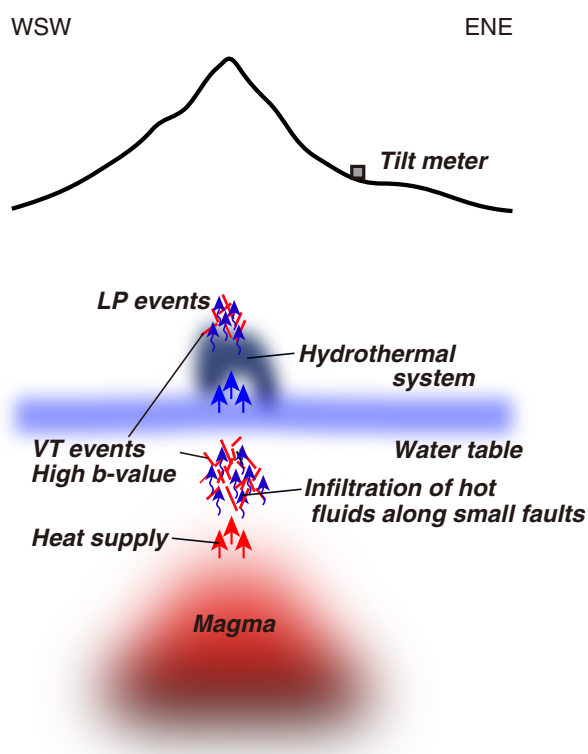

b] 10 minutes before the eruption
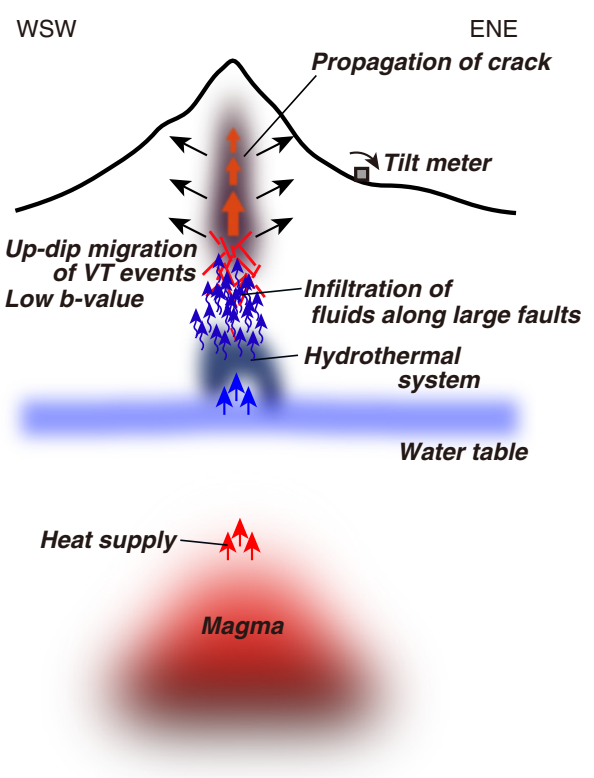

Fig. 9 Schematic figure showing the preparation and precursory stages of the 2014 phreatic eruption of Mount Ontake. a Around the middle of September 2014 (1 to 2 weeks prior to the eruption). b Approximately 10 min before the eruption. Tilt change showing down in the ESE direction is consistent with opening of the shallow vertical conduit 
To our knowledge, the present study was the first to describe the rapid propagation of a vertical conduit during the accelerating stage prior to a phreatic eruption. It is important to capture short-term precursors as early as possible and to raise the alarm for climbers to evacuate from potential eruption sites. Further understanding of the excitation mechanism of phreatic eruptions will require continuous monitoring of seismicity and crustal movement in the vicinity of the summit because the geophysical signals related to the pre-eruption propagation of a vertical crack are too localized to be observed in the far field.

\section{Competing interests}

The authors declare that they have no competing interests.

\section{Authors' contributions}

AK carried out the data processing, phase picking, relocation, and analysis of the continuous data and drafted the manuscript. TT carried out the seismic observation and the data processing and helped draft the manuscript. YY carried out the seismic observation and the data processing and helped draft the manuscript. YM helped draft the manuscript. SH, KM, and TO operated and maintained the seismic stations. All authors read and approved the final manuscript.

\section{Acknowledgements}

We thank JMA, NIED, Nagano Prefecture, and Gifu Prefecture for allowing us to use waveform data collected by their permanent stations. JMA provided the tiltmeter data recorded near the summit (V.ONTN). We are grateful to Y. Shibayama for the dedicated help with the data processing. We thank D. Roman and one anonymous reviewer for useful comments and suggestions. Figures were created using GMT (Wessel and Smith 1995) and spectrogram analysis tool (Miyakawa and Sakai 2008). This study was supported by the Ministry of Education, Culture, Sports, Science and Technology (MEXT) of Japan, under its Earthquake and Volcano Hazards Observation and Research Program and under KAKEN (26900002). This study was also supported by the Earthquake Research Institute cooperative research program.

Received: 15 April 2015 Accepted: 2 July 2015

Published online: 16 July 2015

\section{References}

Aoki Y, Takeo M, Aoyama H, Fujimatsu J, Matsumoto S, Miyamachi H, Nakamichi H, Ohkura T, Ohminato T, Oikawa J, Tanada R, Tsutsui T, Yamamoto K, Yamamoto M, Yamasato H, Yamawaki T (2009) P-wave velocity structure beneath Asama Volcano, Japan, inferred from active source seismic experiment. J Volcanol Geotherm Res 187:272-7

Aoyama H, Oshima H (2008) Tilt change recorded by broadband seismometer prior to small phreatic explosion of Meakan-dake volcano, Hokkaido, Japan. Geophys Res Lett 35:L06307. doi:10.1029/2007GL032988

Barberi F, Bertagnini A, Landi P, Principe C (1992) A review on phreatic eruptions and their precursors. J Volcanol Geotherm Res 52(4):231-46. doi:10.1016/ 0377-0273(92)90046-G

Bertrand EA, Caldwell TG, Hill GJ, Wallin EL, Bennie SL, Cozens N, Onacha SA, Ryan GA, Walter C, Zaino A, Wameyo P (2012) Magnetotelluric imaging of upper-crustal convection plumes beneath the Taupo Volcanic Zone, New Zealand. Geophys Res Lett 39:L02304. doi:10.1029/2011GL050177

Bridges DL, Gao S (2006) Spatial variation of seismic b-values beneath Makushin Volcano, Unalaska Island, Alaska. Earth Planet Sci Lett, 245, 408-415 doi:10.1016/j.epsl.2006.03.010.

Chouet B (1996) Long-period volcano seismicity: its source and use in eruption forecasting. Nature 380:309-16

Cyranoski D (2014) Why Japan missed volcano's warning signs. Nature. doi:10.1038/nature.2014.16022

Earthquake Research Institute in the University of Tokyo (2014), http:// www.data.jma.go.jp/svd/vois/data/tokyo/STOCK/kaisetsu/CCPVE/shiryo/130/ 130_no01.pdf. Accessed 1 April 2015.

Geospatial Information Authority of Japan (2014), http://www.gsi.go.jp/BOUSAI/ h26-ontake-index.html. Accessed 1 April 2015.
Hayashi Y, Morita Y (2003) An image of a magma intrusion process inferred from precise hypocentral migrations of the earthquake swarm east of the IzU Peninsula. Geophys J Int 153:159-74

Hirose F, Nakajima J, Hasegawa A (2008) Three-dimensional seismic velocity structure and configuration of the Philippine Sea slab in southwestern Japan estimated by double-difference tomography. J Geophys Res 113:B09315. doi:10.1029/2007JB005274

Hubbert MK, Rubey WW (1959) Role of fluid pressure in mechanics of overthrust faulting 1. Mechanics of fluid-filled porous solids and its application to overthrust faulting. Geol Soc Am Bull 70(2):115-66

Ikami A, Yoshii T, Kubota S, Sasaki Y, Hasemi A, Moriya T, Miyamachi H, Matsu'ura R, Wada K (1986) A seismic refraction profile in and around Nagano Prefecture, Central Japan. J Phys Earth 34:457-74

Japan Meteorological Agency (2014), Rep. Coordin. Committee on Prediction of Volcanic Eruption, http://www.data.jma.go.jp/svd/vois/data/tokyo/STOCK kaisetsu/CCPVE/shiryo/130/130_no01.pdf. Accessed 1 April 2015.

Kato A, lidaka T, Kurashimo E, Nakagawa S, Hirata N, Iwasaki T (2007) Delineation of probable asperities on the Atotsugawa fault, central Japan, using a dense temporary seismic network. Geophys Res Lett 34:L09318. doi:10.1029/2007GL029604

Kato A, Obara K, Igarashi T, Tsuruoka H, Nakagawa S, Hirata N (2012) Propagation of slow slip leading up to the 2011 Mw 9.0 Tohoku-Oki earthquake. Science 335:705-8. doi:10.1126/science.1215141

Kato A, Fukuda J, Obara K (2013) Response of seismicity to static and dynamic stress changes induced by the 2011 M9.0 Tohoku-Oki earthquake. Geophys Res Lett 40, doi:10.1002/grl.50699.

Kumagai H, Chouet BA (2000) Acoustic properties of a crack containing magmatic or hydrothermal fluids. J Geophys Res 105(B11):25,493-25,512

Lahr JC, Chouet BA, Stephens CD, Power JA, Page RA (1994) Earthquake classification, location and error analysis in a volcanic environment: implications for the magmatic system of the 1989-1990 eruptions at Redoubt Volcano, Alaska. J Volcanol Geotherm Res 62:137-51

Maeda Y, Kumagai H, Lacson RJ, Figueroa MS, Yamashina T, Ohkura T, Baloloy AV (2015) A phreatic explosion model inferred from a very long period seismic event at Mayon Volcano, Philippines. J Geophys Res Solid Earth 120:226-42. doi:10.1002/2014JB011440

McNutt SR (2005) Volcanic seismology. Annu Rev Earth Planet Sci 32:461-91

Miyakawa K, Sakai S (2008) Development of a spectrogram analysis tool for seismic waveform data and its application to MeSO-net for noise survey, Technical Research Report, Earthquake Research Institute, the University of Tokyo, 14, 13-22.

Mordret A, Jolly AD, Duputel Z, Fournier N (2010) Monitoring of phreatic eruptions using Interferometry on Retrieved Cross-Correlation Function from Ambient Seismic Noise: results from Mt. Ruapehu, New Zealand. J Volcanol Geotherm Res 191:46-59

Nakajima J, Hasegawa A (2006) Anomalous low-velocity zone and linear alignment of seismicity along it in the subducted Pacific slab beneath Kanto, Japan: reactivation of subducted fracture zone? Geophys Res Lett 33:L16309. doi:10.1029/2006GL026773

Nakamichi H, Kumagai H, Nakano M, Okubo M, Kimata F, Ito Y, Obara K (2009) Source mechanism of very-long-period event at Mt. Ontake, central Japan: response of a hydrothermal system to magma intrusion beneath the summit. J Volcanol Geotherm Res 187:167-77

Roman DC, Cashman KV (2006) The origin of volcano-tectonic earthquake swarms. Geology 34:457-60

Shelly DR, Hill DP (2011) Migrating swarms of brittle-failure earthquakes in the lower crust beneath Mammoth Mountain, California. Geophys Res Lett 38:L20307. doi:10.1029/2011GL049336

Shelly DR, Beroza GC, Ide S (2007) Non-volcanic tremor and low-frequency earthquake swarms. Nature 446:305-7. doi:10.1038/nature05666

Shi Y, Bolt BA (1982) The standard error of the magnitude-frequency b-value. Bull Seism Soc Am 72:1677-87

Smithsonian Institution (2015) Bulletin of the Global Volcanism Network, http://www.volcano.si.edu/search_eruption.cfm. Accessed 1 April 2015.

Tanaka S, Hamaguchi H, Nishimura T, Yamawaki T, Ueki S, Nakamichi H, Tsutsui T, Miyamachi H, Matsuwo N, Oikawa J, Ohminato T, Miyaoka K, Onizawa S, Mori T, Aizawa K (2002) Three-dimensional P-wave velocity structure of Iwate volcano, Japan from active seismic survey. Geophys Res Lett 29, 10.1029/2002GL014983.

Terakawa T (2014) Evolution of pore fluid pressures in a stimulated geothermal reservoir inferred from earthquake focal mechanisms. Geophys Res Lett 41:7468-76. doi:10.1002/2014GL061908 
Terakawa T, Yamanaka Y, Nakamichi H, Watanabe T, Yamazaki F, Horikawa S,

Okuda T (2013) Effects of pore fluid pressure and tectonic stress on diverse seismic activities around the Mt. Ontake volcano, central Japan. Tectonophysics 608:138-48

Utsu T (1965) A method for determining the value of $b$ in a formula log $n=a-b M$ showing the magnitude frequency for earthquakes. Geophys Bull Hokkaido Univ 13:99-103

Waite GP, Chouet BA, Dawson PB (2008) Eruption dynamics at Mount St. Helens imaged from broadband seismic waveforms: interaction of the shallow magmatic and hydrothermal systems. J Geophys Res 113, B02305, doi:10.1029/2007JB005259.

Wessel P, Smith WHF (1995) New version of the generic mapping tools released. Eos Trans AGU 76:329

Wiemer S, Wyss M (2000) Minimum magnitude of completeness in earthquake catalogs: examples from Alaska, the western United States, and Japan. Bull Seismol Soc Am 90:859-69

Wyss M, Shimazaki K, Wiemer S (1997) Mapping active magma chambers by b-value beneath the off-Ito volcano, Japan. J Geophys Res 102:20413-22

Zhang H, Thurber CH (2003) Double-difference tomography: the method and its application to the Hayward fault, California. Bull Seismol Soc Am 93:1875-89. doi:10.1785/0120020190

Submit your manuscript to a SpringerOpen ${ }^{\circ}$ journal and benefit from:

- Convenient online submission

- Rigorous peer review

- Immediate publication on acceptance

Open access: articles freely available online

- High visibility within the field

- Retaining the copyright to your article

Submit your next manuscript at $>$ springeropen.com 